\title{
Desrespeito e patologias sociais na Filosofia de Axel Honneth
}

\section{Disrespect and social pathologies in the philosophy of Axe Honneth}

Tiago Porto Pereira*

Recebidoem: 08/2015 Aprovado em: 02/2016

\begin{abstract}
Resumo:Dentre as escolas de pensamento situadas no campo de estudo denominado Filosofia Política e Social, a Teoria Crítica recebe um lugar de destaque. Originária da Alemanha, buscava estudar os efeitos sociopolíticos do capitalismo a partir de um referencial marxista, utilizando uma metodologia multidisciplinar que abrangia Filosofia, Psicanálise, Ciências Sociais, Direito entre outras áreas de conhecimento. Longeva, a tradição inaugurada em Frankfurt no limite entre 1929 e 1930 por Theodor Adorno e Max Horkheimer, vive atualmente a sua terceira geração, sendo representada principalmente por Axel Honneth. Ainda que os referenciais teóricos dos seus integrantes fossem heterogêneos, passando de Karl Marx por Sigmund Freud e G.W.F. Hegel, uma categoria de estudo perpassou as três gerações, recebendo tônicas diferenciadas quanto ao seu diagnóstico: as patologias sociais. No presente artigo, pretende-se analisar de que forma Axel Honneth articula esse tópico dentro do seu corpus teórico. Para tanto, procederemos nossa investigação partindo inicialmente do conceito de desrespeito, fundamental para entendermos o alicerce conceitual empregado pelo filósofo; em seguida, nos concentraremos propriamente nas patologias sociais, analisando sobretudo a ideologia, a reificação e os paradoxos de individualização, enfermidades trabalhadas pelo autor; finalmente, encerramos este trabalho com um estudo do sentimento de injustiça e com a conclusão se Honneth oferece ou não uma solução prescritiva quanto as patologias sociais.

Palavras-chave: Desrespeito, Patologias sociais, Reconhecimento.
\end{abstract}

Abstract:Among the schools of thought situated within the field of study called Social and Political Philosophy, Critical Theory receives a prominent place. Originally from Germany, it

\footnotetext{
*Mestrando em Filosofia pela PUCRS, bolsista pelo CNPq.

Problemata: R. Intern. Fil. v. 7. n. 1 (2016), p. 169-191 ISSN 2236-8612 doi:http://dx.doi.org/10.7443/problemata.v7i1.25336
} 
soughts to study the socio-political effects of capitalism from a Marxist framework, using a multidisciplinary approach covering Philosophy, Psychoanalysis, Social Sciences, Law and other areas of knowledge. The long-lived tradition started in Frankfurt between 1929 and 1930 by Theodor Adorno and Max Horkheimer lives nowadays its third generation, represented mainly by Axel Honneth. Although the theoretical framework of its members were heterogeneous, from Karl Marx to Sigmund Freud and G.W.F. Hegel, a category of study pervaded the three generations as getting different tonics to their diagnosis: social pathologies. In this article, we intend to analyze how Axel Honneth articulates this topic within his theoretical corpus. For this purpose, we will proceed our investigation initially by the concept of disrespect, essential to understanding the conceptual foundation utilized by the philosopher. After that, we focus specifically on social pathologies, especially analyzing ideology, reification and the individualization paradoxes, infirmities worked by the author. Finally, we conclude this paper with a study of the sense of injustice and the conclusion if Honneth provides a prescriptive solution or not to social pathologies.

Keywords: Disrespect, Social pathologies, Recognition.

\section{Considerações iniciais}

$\mathrm{O}$ século $\mathrm{XX}$ forneceu à Filosofia algumas das maiores teorias sobre o indivíduo e suas relações entre seus semelhantes e o meio onde vivem. Com a emergência do capitalismo, vários pensadores se debruçaram sobre a questão das consequências dessa forma de organização política e social, alguns endossando suas características positivas, outras, ao contrário, buscavam apontar as consequências negativas para os indivíduos inseridos dentro desse sistema. Dentro deste grupo, foi de grande influência o Instituto para Pesquisa Social fundado por Theodor Adorno e Max Horkheimer em Frankfurt no final do ano de 1929, que deu origem ao que ficou conhecido como Teoria Crítica: um estudo da sociedade no qual se buscava um foco interdisciplinar prático, tendo entre seus componentes estudiosos das Ciências Sociais, Psicanálise, Filosofia e Direito. Entre os chamados "frankfurtianos", podemos citar Hebert Marcuse, Eric Fromm, Franz Neumann, Leo Löwenthal, além dos próprios Adorno e Horkheimer.

Longeva, a tradição iniciada pela Escola de Frankfurt vive a sua terceira geração: a primeira, com os fundadores assinalados acima; a segunda, teve Jürgen Habermas como

Problemata: R. Intern. Fil. v. 7. n. 1 (2016), p. 169-191 ISSN 2236-8612 
maior expoente; e a atual, onde encontramos nomes como Seyla Benhabib e Axel Honneth como representantes da Teoria Crítica. Desde a sua fundação, muita coisa mudou quanto ao enfoque teórico dado pelos filósofos vinculados à tradição, permanecendo questões de cunho social e prático, além de estudos interdisciplinares. Contudo, por mais heterogêneas que sejam as filosofias das três gerações citadas, um assunto em comum os liga estreitamente: as patologias sociais. De acordo com Honneth,

Through all their disparateness of method and object, the various authors ofthe Frankfurt School are united in the idea that the living conditions of modern capitalist societies produce social practices, attitudes, or personality structures that result in a pathological deformation of our capacities for reason. It is this theme that establishes the unity of Critical Theory in the plurality of its voices.(HONNETH, 2009, p. vii)

Partindo da teoria psicanalítica de Freud, a primeira geração apontava os problemas causados sobretudo pelo sistema capitalista quanto ao desenvolvimento de neuroses e alienação provocadas nos indivíduos. A segunda e terceira geração, representadas por Habermas e Honneth, se afastam da tradição freudiana e buscam apoio na psicologia social de George Herbert Mead. Fundamentando o seu trabalho no reconhecimento, Honneth, que será o foco do nosso trabalho, assinala que os desrespeitos sofridos pelos indivíduos sociais deixam marcas psíquicas, que podem progredir e tornarem-se patologias sociais com efeitos ainda mais graves.

No desenvolver do presente artigo, iremos nos focar na categoria de patologia social conforme o abordado por Honneth, partindo dos desrespeitos assinalados no livro Luta por reconhecimento; em seguida, exporemos como o filósofo vem desenvolvendo o seu trabalho no que tange patologias sociais, nos limitando a três delas: reificação, ideologia e paradoxosdeindividualização, dada a extensão do assunto; finalmente, concluiremos este trabalho com dois tópicos: qual é o papel desempenhado pelos desrespeitos dentro da teoria do reconhecimento e se Axel Honneth estabelece um sistema de prevenção ou de recuperação para as patologias sociais, isto é, se há algum meio que permita um tratamento dos indivíduos que padecem com essas "doenças" desenvolvidas em meio social. 


\section{Desrespeito e sentimentos de injustiça}

Axel Honneth sustenta a sua Teoria do Reconhecimento sobre o tripé hegeliano estabelecido nos escritos de Jena, qual seja, o amor, o direito e a solidariedade. Dentro dessas esferas de reconhecimento, o indivíduo gradualmente constrói autorrelações positivas que permitem a evolução do sujeito até a efetivação da sua vida dentro da sociedade civil. Contudo, sempre há o risco de haver frustrações das expectativas de reconhecimento e desrespeitos que o indivíduo possa vir a sofrer, impedindo que possa desenvolver sua vida de forma saudável. Com essa abordagem, o filósofo busca primeiramente definir quais são as formas de desrespeito para em seguida concentrar-se em responder de que forma estas experiências, que podem afetar tão profundamente os indivíduos, podem impulsionar as lutas por reconhecimento. Tendo isso em vista, Honneth define três formas de desrespeito em oposição às esferas de reconhecimento ${ }^{1}$, sendo elas maus-tratos/violação, privação de direitos e degradação.

Os maus-tratos são posicionados contra a primeira esfera de reconhecimento, ou seja, a que representa o amor. De acordo com o filósofo, essas práticas de violência corporal que visam retirar de outra pessoa toda a sua autonomia quanto ao dispor do seu próprio corpo livremente representam uma forma de rebaixamento pessoal. Isso decorre de que qualquer forma de utilizar o corpo de outrem contra a sua vontade configura-se em uma forma de opressão e de humilhação que marcarão profundamente a vida psíquica e a autorrelação do indivíduo. Tais ações não ferem apenas ao corpo da vítima, pois a sensação da dor física, conforme observado por Honneth, vem acompanhada do sentimento de estar submetido à vontade de outra pessoa, sem proteção alguma, ao ponto mesmo de perderse a noção de realidade: a vítima fantasia que se trata de um sonho ruim, perde a noção do tempo, regride mentalmente a um estado infantil, etc. Além disso, o prejudicado perde a capacidade de confiar no outro, em si e no mundo, desenvolvendo em alguns casos um sentimento de culpa como se fosse responsável por sofrer essa espécie de violência. Existem também os casos onde a violação é utilizada como arma de guerra, onde os exércitos utilizam de tal ato opressor contra a população do Estado inimigo ou seus oponentes vencidos. Dessa forma, as estruturas de confiança aprendidas na esfera do amor 
familiar vão a baixo, causando uma situação onde a desconfiança quanto ao próximo se torna uma constante e a autossegurança do indivíduo é destroçada.

Os maus-tratos físicos de um sujeito representam um tipo de desrespeito que fere duradouramente a confiança, aprendida através do amor, na capacidade de coordenação autônoma do próprio corpo; daí a consequência ser também, com efeito, uma perda de confiança em si e no mundo, que se estende até as camadas corporais do relacionamento prático em outros sujeitos, emparelhada com uma espécie de vergonha social. (HONNETH, 2003, p. 215)

A próxima forma de desrespeito é a privação de direitos, oposta à esfera de reconhecimento jurídico. Honneth assinala que a negação sistemática de direitos fundamentais para que o indivíduo possa desempenhar plenamente seu papel de cidadão implica o rebaixamento moral desse sujeito, levando-o a não se considerar uma pessoa digna frente aos seus pares, configurando-se assim uma espécie de ostracismo social. Pontualmente, o que caracteriza esse tipo de desrespeito é uma combinação de restrições de autonomia daqueles afetados somado a falta de reconhecimento por parte dos seus parceiros de interação dentro de uma estrutura onde todos gozam dos mesmos direitos morais. As consequências da privação de direitos para o sujeito são uma violação de suas expectativas intersubjetivas de ser reconhecido pelos demais membros da sua sociedade como uma pessoa capaz de formar juízos morais, acarretando a perda de autorrespeito, ou seja, o indivíduo não considera a si mesmo como um ser dotado de direitos em paridade com os demais membros da sociedade ${ }^{2}$.

A última forma de desrespeito esboçada por Honneth trata-se da degradação ou insulto, situado em oposição à esfera de reconhecimento representada pela solidariedade. Esse tipo de desrespeito parte da depreciação de determinados indivíduos ou grupos inteiros, reduzindo o status dos sujeitos de forma que se crie uma hierarquia social onde grupos detém maior prestígio que outros ou relegam a estes um valor de inferioridade, retirando-os a capacidade de atribuir valor social aos seus atos. Dessa forma, as pessoas atingidas perdem a capacidade de referir-se a suas ações como algo realmente produtivo para a sociedade como um todo, sendo vistos pelos demais como "cidadãos de baixa categoria" ou como párias sociais. Aqueles

Problemata: R. Intern. Fil. v. 7. n. 1 (2016), p. 169-191 ISSN 2236-8612 
que sofrem com essas ações são acometidos pela perda da autoestima, visto que não se compreendem como membros produtivos da sociedade na qual estão inseridos e não recebem o reconhecimento social que é vital para o desenvolvimento do indivíduo dentro de um grupo, visto que a solidariedade de grupos encoraja a autorrealização dos sujeitos ${ }^{3}$.

Honneth observa que os dois últimos tipos respondem a uma disposição histórica, sofrendo alterações com o passar dos anos. Dessa forma, grupos que sofriam algum tipo de rebaixamento social passaram a ter maior participação social efetiva à medida que os anos foram passando. Para citar um exemplo, lembremos que até o princípio do século $\mathrm{XX}$ às mulheres eram delegadas apenas as tarefas do lar como cuidar da casa e educar os filhos, enquanto cabia ao homem sustentar sua família com os vencimentos do seu salário. Além de ficarem estanques ao feudo familiar, a elas também era negado o direito ao voto, visto que não eram consideradas capazes de compreender e decidirem assuntos sociais. Com a progressão da história e as mudanças paradigmáticas da sociedade póstradicional, as mulheres não só conquistaram o direito ao sufrágio universal como gradativamente se inseriram no mercado de trabalho, compartilhando com os homens as mesmas tarefas de suprir o grupo familiar e proporcionar educação aos filhos. Nos termos honnethianos, elas conquistaram o seu reconhecimento mediante conflitos morais que impulsionaram a sociedade a uma evolução e expansão de direitos.

Saavedra (2007) observa que Honneth adota o termo "patologia social" (veremos em detalhe a seguir) para esclarecer essas formas de desrespeito, reportando-se, por sua vez, a sintomas físicos deixados por elas. Dessa forma, os sintomas corporais do sofrimento psíquico desses indivíduos devem ser interpretados como manifestações externas dessa enfermidade interior. Quanto aos sintomas externos das patologias, diz Honneth:

[...] é típico dos três grupos de experiências de desrespeito [...] o fato de suas consequências individuais serem sempre descritas com metáforas que remetem a estados de abatimento do corpo humano: nos estudos psicológicos que investigam as sequelas pessoais da experiência de tortura e violação, é frequente falar de "morte psíquica"; nesse meio-tempo, 
no campo de pesquisa que se ocupa, no caso da escravidão, com a elaboração coletiva da privação de direitos e da exclusão social, ganhou cidadania o conceito de "morte social"; e, em relação ao tipo de desrespeito que se encontra na degradação cultural de uma forma de vida, é a categoria de "vexação" que recebe um emprego preferencial. (HONNETH, 2003, p. 218-219).

Portanto, somente as experiências de injustiça que causem alguma espécie de patologia devem ser interpretadas como fenômenos de desrespeito ${ }^{4}$.

Ademais, Honneth argumenta, usando como base os estudos de John Dewey, que o desrespeito acaba agindo como uma espécie de freio social, pois ele pode impedir que os indivíduos ou os grupos que foram lesados partam para a ação. Mesmo que paralisados e impotentes, as pessoas dependem dos seus pares, o que ressalta a sua inclusão dentro de uma grande rede intersubjetiva. Partindo, então, desta dependência, as experiências de desrespeito podem levar os sujeitos a agirem em busca da mudança do estado ao qual estão, fornecendo uma base para as lutas por reconhecimento, conforme abordaremos ao final do presente artigo. Veremos, a seguir, como Honneth aborda as patologias sociais dentro do seu corpus filosófico, categoria importante para as três gerações da Teoria Crítica.

\section{Patologias sociais}

A filosofia social de Honneth, seguindo a tradição da Teoria Crítica, aponta que os indivíduos que vivem em sociedade devem evitar as patologias sociais a fim de conseguirem desenvolver uma boa vida e alcançarem suas autorrealizações. Para o autor de Luta pelo reconhecimento, as patologias sociais são tendências patológicas da sociedade moderna que fazem com que a autorrealização individual seja algo impossível. Ainda que a categoria de patologia social fosse ponto importante para a primeira geração dos frankfurtianos, Honneth nas suas primeiras obras não aprofunda esse conceito. Deranty (2009) observa que estas não figuravam um papel central no livro Luta pelo Reconhecimento, vindo a ser desenvolvida propriamente em 2002, dez anos depois. Até então, essa categoria estava atrelada aos sentimentos de injustiça 
que, por sua vez, desenvolviam-se a partir dos desrespeitos sofridos pelos indivíduos.

[...] social pathology does not yet appear as a central category in 1992. As the succinct reconstruction has just shown, the notion logically completes the model of a critical theory grounded in the "feeling of injustice". When "injuries of deep-seated recognition expectations" take a systematic form as a result of a specific organization of the social-cultural order, that social context, because of the injuries it inflicts on subjects, is tantamount to a "social pathology". This concept emerges for the first time at the end of chapter 7, after the study of Sartre's concept of "objective neurosis", which Honneth characterizes as "pathology of recognition relations". However, it is only in the major chapter that introduces the volume Honneth edited in 2002, Pathologien des Sozialen. Die Aufgabe der Sozialphilosophie, that the theory of recognition is explicitly completed with the notion of social pathology.(DERANTY, 2009, p. 319-320), grifo do autor.

No decorrer da sua produção filosófica após 2002, onde as patologias sociais passam a ter um papel mais presente dentro da Teoria do Reconhecimento, Honneth elenca diversas espécies de padecimentos que se inserem sob esta categoria. Neste artigo, trataremos de apenas três delas: a ideologia, a reificação e os paradoxos de individualização.

\section{Ideologia}

O conceito de ideologia significa um conjunto de ideias, doutrinas ou visões de mundo que são compartilhados por um grupo em determinada sociedade. Inicialmente empregada na época de Napoleão Bonaparte por Destutt de Tracy, significava inicialmente "ciência das ideias"; contudo, após este cair em desgraça aos olhos do imperador, o termo recebeu a conotação negativa de "distorção da realidade". Assim, o conceito tem sido trabalhado por diversos pensadores, mas recebeu sua definição filosófica mais difundida a partir de Karl Marx. Este defendia que ela causava a alienação dos homens ao separar sua consciência do trabalho realizado, além de ser uma superestrutura composta por ideias que movem a "vida real", 
que mascaram a realidade sob um discurso sobre o mundo. Dessa forma, esse conceito foi amplamente difundido pelos filósofos que buscam apreender o que ocorre na sociedade, empregando diagnósticos e buscando soluções para este problema. Entre tantos estudiosos, aqui também entram os membros da Teoria Crítica.

Tendo essa introdução em vista, vejamos como Axel Honneth compreende esse conceito e o aplica à sua Teoria do Reconhecimento. O filósofo busca investigar como o conceito de ideologia se liga a crenças de primeira ordem, especialmente como se articula com as estruturas básicas, ordens e funcionalidades da sociedade. Segundo ele, os atores sociais padecem de patologias cognitivas, visto que não conseguem perceber de onde surgem tais crenças. Essa patologia em especial é proveniente de que as pessoas geralmente não estão cientes - ao menos de forma imediata - de que o consenso social é "sensível" e "moldado pelos poderes sociais predominantes e interesses sociais de classe específicos"5.

Zurn (2011) observa que Honneth considera as patologias sociais como desordens de segunda ordem, não sendo diferente com a concepção clássica de ideologia desenvolvida por Marx. Zurn assinala que podemos verificar que crenças ideológicas em aspecto clássico fazem parte daquele grupo de desordens ao compará-las com crenças triviais equivocadas. Em ambos os casos, há presente um equívoco no nível de primeira ordem, ou seja, o indivíduo encontra-se convencido erroneamente quanto a algo. Contudo só podemos identificá-la quando a ideologia é uma crença errônea sistematicamente anexada às formações sociais que afetam a formação de crenças e estabilização em segunda ordem, seja escondendo ou reprimindo a reflexibilidade necessária para que os participantes sociais possam perceber as estruturas de formação de crenças e as conexões entre estruturas cognitivas-culturais e o ordenamento material da sociedade ${ }^{6}$.

Para clarificar um pouco do que se trata a ideologia sob aspectos críticos, um desacordo sobre a nomenclatura de um determinado objeto pode facilmente ser resolvido com base no esclarecimento, visto que nem todos possuem o mesmo grau de instrução, seja ela específica ou não. Tal tipo de crença falsa não se configura em uma deformação da percepção de mundo baseada em um processo cognitivo de segunda ordem, visto que o mal-entendido pode ser solucionado rapidamente. Agora, quando lidamos com convicções mais profundas, como, por

Problemata: R. Intern. Fil. v. 7. n. 1 (2016), p. 169-191 ISSN 2236-8612 
exemplo, a de que a base do sucesso financeiro está na iniciativa privada e o acumulo de renda é algo a ser alcançado a todo custo, tratamos de crenças ideológicas. Dessa forma, lidamos com uma deformação de segunda ordem dos processos de formação de certezas baseada na percepção de um mundo socioeconômico constituído, ou seja, uma crença de primeira ordem sobre uma sociedade que nos é dada. Tanto a certeza do que é uma sociedade (capitalista, no caso) de fato quanto a deformação cognitiva são úteis para determinados interesses sociais e estão fortemente enraizados nela, não sendo tarefa fácil corrigir essa espécie de convicção errônea. Quando confrontados com argumentações contrárias a esse tipo de crença ideológica, os indivíduos tendem a rechaçar as informações alegando que se tratam de dados parciais, enviesados ou exceções às regras, uma maneira de tentar preservar suas crenças na estrutura social aparentemente real, naturalizando e reproduzindo esse tipo de pensamento baseado em uma pretensa solidez socioeconômica.

Contudo, ideologia não se restringe apenas a crenças cognitivas, mas também se liga à questões normativas. Nos trabalhos mais recentes de Honneth, encontramos uma atenção especial na busca de solucionar a questão de como conceitualizar formas ideológicas de reconhecimento, sobretudo de que forma podemos diferenciá-las de formas de reconhecimento devidamente saudáveis e produtivas socialmente. Sendo assim, o filósofo procura uma maneira de identificar dentro das formas de reconhecimento possíveis aquilo que pode ser identificado como distorções ideológicas em oposição ao que é produtivo para a sociedade, instância de reconhecimento intersubjetivo. A conclusão a qual chega o seu estudo é que atos de reconhecimento, em sua essência, assumem uma característica ideológica quando surge uma lacuna entre reconhecimento avaliativo e condições institucionais e materiais que são necessárias para a efetivação daquele reconhecimento.

Zurn (2011) observa que a forma com que Honneth desenvolve a sua visão de reconhecimento ideológico não se afasta muito da versão clássica marxiana, visto que ambas dependem de distúrbios de segunda ordem, que poderíamos chamar de falso reconhecimento ou não-reconhecimento. Assim, ambos estão profundamente enraizados em processos deformatórios de segunda ordem, processos institucionalizados de formação e estabilização de valoração recognitiva 
interpessoal. Tais deformações servem sistematicamente a interesses sociais por manter estruturas de opressão sem a necessidade de coerção explícita, uma vez que os próprios indivíduos da sociedade são responsáveis pela coerção social indireta. O reconhecimento ideológico, portanto, não é facilmente corrigido, mas ao contrário, é reforçado socialmente pelos indivíduos e os seus processos são naturalizados ao esconder ou reprimir os distúrbios de segunda ordem que por ela é causado ${ }^{7}$.

\section{Reificação}

A partir do ciclo de palestras feitas na University of California sob o título Reification, Honneth reinterpreta o conceito de reificação a partir da leitura de Marx e, sobretudo, de Lukács, buscando suporte para a sua nova elaboração do reconhecimento nas teorias de Martin Heidegger, John Dewey, Theodor Adorno e Stanley Cavell. Tradicionalmente, entende-se por reificação o processo de "objetificação" das pessoas que nos cercam, ou seja, tratá-las como coisas desprovidas de sentimentos que servem apenas a determinados propósitos. A reinterpretação feita pelo filósofo busca contrastar duas posições distintas, a saber, envolvimento interessado (interested involvement) e uma posição de objetivação cognitiva independente. Conforme sua teoria, o envolvimento interessado é tanto ontogênico quanto conceitualmente anterior à posição de objetivação cognitiva ${ }^{8}$. Essa relação com os outros designa um modo de interagir com o mundo de forma compromissada e afetiva, ou seja, uma relação baseada em empatia com os demais seres que nos cercam, emprestando à categoria de reconhecimento uma forma realmente existencial e envolvente. Sendo assim, o reconhecimento indica que nossa interação primária com o mundo se dá por meio de um compromisso prático, positivo ou afirmativo com os demais indivíduos, em vez de ser uma postura meramente contemplativa, separada (detached) ou uma posição cognitiva ${ }^{9}$. Essa interpretação ontológica de reconhecimento é posta em contraste com posições que denotam comunicatividade e intencionalidade.

De acordo com Petherbridge (2011), Honneth passa a trabalhar com a sua teoria de forma "moral epistemológica", visto que o reconhecimento começa a ser visto como algo 
anterior a fatores cognitivos de reconhecimento de identidades alheias:

Honneth had already begun to develop this theoretical
stance in his conception of the "moral epistemology of
recognition" with affective and expressive affirmation
at its core. For Honneth, recognition means much more
than merely "perceiving", "identifying" or "cognising"
the other in terms of acknowledging the others identity.
Rather, 'recognition precedes cognition' both
ontogenetically and conceptually; it refers to an
affirmative affective stance towards the world that
precedes all forms of interaction or recognition [...].
(PETHERBRIDGE, 2011, p. 28-29)

Posto isso, podemos dizer que Honneth entende que o conceito de reificação parte de ações que visam objetificar outros indivíduos, o mundo ou a si mesmo, ao passo que se esquece a importância das conexões constitutivas que uma postura objetivante exerce sobre as interações que temos com os outros. Assim, a objetivação reificante é um esquecimento ativo da prioridade de reconhecimento para a cognição, sendo este sistematicamente reproduzido, deformando o tecido do reconhecimento intersubjetivo que é fundamental para manter uma estrutura ética para a vida social ${ }^{10}$.

It is this element of forgetting, of amnesia, that I would like to establish as the cornerstone for a redefinition of the concept of "reification." To the extent to which in our acts of cognition we lose sight of the fact that these acts owe their existence to our having taken up an antecedent recognitional stance, we develop a tendency to perceive other persons as mere insensate objects. (HONNETH, 2005, p. 129)

Honneth ainda subdivide os tipos de esquecimento que causam a reificação de outras pessoas em dois tipos distintos, um interno e outro externo ao indivíduo: esquecimento visando objetivos e por pensamentos seletivos. O primeiro tipo parte de ações onde se visa o resultado último de determinado objetivo com tamanho afinco que tudo aquilo que não está relacionado com esta meta desaparece. Podemos exemplificar este caso com o que ocorre durante a prática de algum esporte, onde o oponente é visto apenas como um obstáculo a ser superado a caminho da vitória ou nos casos de possível ascensão 
empresarial, onde os candidatos não percebem a humanidade dos seus colegas e fazem de tudo para ser promovidos, mesmo que para isso seja necessário passar por cima uns dos outros. $\mathrm{O}$ segundo tipo de reificação parte de esquemas de pensamento que influenciam interpretações seletivas de determinados fatos sociais que poderiam reduzir nossa atenção para eventos ou circunstâncias de valor crucial em determinados momentos ${ }^{11}$. Isso significa ignorar conscientemente a existência de informações importantes que poderiam derrubar uma tese ou estrutura social, por exemplo. Nesse caso em específico, o filósofo assinala que o termo mais apropriado não seja "esquecimento" mas "negação" ou "defensiva"12.

Além desses pontos, a reificação, conforme Honneth a compreende, pode ser apreendida com relação a objetos alheios ao mundo social e a autorrelações internas do mundo interior dos sujeitos. No que toca ao mundo físico, ela significa o esquecimento do que significam os objetos e as relações para as demais pessoas. A reificação de objetos se dá quando o sujeito não consegue pensar um objeto fora do contexto específico no qual é utilizado dentro do seu cotidiano social, enquanto a reificação de si responde a relações distorcidas dos estados internos do indivíduo, onde este vem a esquecer que a sua relação consigo mesmo é uma relação prática, uma forma de reconhecimento interior possibilitada pelas relações com as demais pessoas em meio social.

Zurn (2011) observa que Honneth emprega uma bipartição quanto a autorreificação: por um lado, há uma forma denominada pelo filósofo de "detectivismo" (detectivism), onde os sujeitos tomam seus estados internos como algo dado empiricamente, sem serem objetos de transformação através de atos de autorreflexão, mas ao contrário, como estados de coisas que devem ser apenas catalogados e apreendidos ${ }^{13}$. Para citar um exemplo, isso ocorre quando um indivíduo encontra uma situação onde ele pode assumir uma outra identidade, seja por vontade própria ou a pedido de outrem, como na criação de um perfil falso dentro de redes sociais da Internet ou em trabalhos de telemarketing onde os funcionários assumem uma identidade conforme o perfil da empresa e segue um script de atendimento formalizado pelo empregador. Do outro lado, encontra-se o tipo de reificação nomeada por Honneth de "construtivismo", onde os sujeitos assumem uma posição de instrumentalização dos seus estados internos ao acreditar que estes estão à disposição

Problemata: R. Intern. Fil. v. 7. n. 1 (2016), p. 169-191 ISSN 2236-8612 
sempre que necessário, bastando acessá-los por um ato de vontade, representando um material extremamente plástico que pode ser moldado conforme as regras sociais ou interesses próprios $^{14}$. Tal coisa acontece quando uma pessoa é empregada em uma empresa onde o nível de cobrança é muito alto, frente ao alto nível de rotatividade de funcionários dentro de uma corporação onde os planos de carreira a longo prazo são substituídos por formas de trabalho terceirizado e mais flexível. Ainda conforme Zurn (2011), nas duas espécies de autorreificação expostas há presente o esquecimento do reconhecimento interno dos indivíduos, onde eles deixam de lado os seus desejos e sentimentos pois acreditam que estes são princípios articuláveis e passíveis de autoconfiguração, visando uma autopromoção para outrem ou imaginado que os estados internos podem ser minimizados ou maximizados conforme os padrões de comportamento humano dados socialmente ${ }^{15}$.

\section{Paradoxos de individualização}

Levando em consideração as mudanças sociais a partir dos anos 1960, Honneth traça um diagnóstico daquilo que vai chamar de "formas paradoxais de individualismo"16. Segundo o seu estudo, houve uma proliferação de reivindicações de autorrealização nas sociedades ocidentais mais desenvolvidas. Ainda que de um ponto de vista objetivo o desenvolvimento possa proporcionar um aumento nas possibilidades qualitativas de liberdades individuais, por outro lado, a partir do ponto de vista subjetivo as expectativas por autorrealização exercem sobre as pessoas uma grande pressão devido à crescente demanda de tarefas. Nas palavras de Honneth: "[...] whatever the individual social causes, [...] forms of life had become strongly individualized: members of the Western societies were compelled, urged or encouraged, for the sake of their own future, to place themselves at the center of their own life plans and lives." (HONNETH, 2012). Assim, essa forma de individualismo acaba levando os sujeitos a desenvolver "sintomas patológicos" de esvaziamento particular, juntamente da falta de sentido ou de propósito, no campo psicológico; ademais, surgem sintomas sociológicos de "ideologia pervasiva de responsabilidade pessoal", que resulta na desinstitucionalização neoliberal ${ }^{17}$. 
Conceitualmente, uma reivindicação de autorrealização requer que a noção de autorrealização do indivíduo seja compreendido (conteúdo de primeira ordem) como um emergir natural da apropriação da história de vida e caráter do indivíduo, em uma segunda ordem de reflexibilidade. Tal coisa perde a sua autenticidade quando responde a apenas um dos pontos, sendo que ou o conteúdo de primeira ordem não corresponde aos anseios do indivíduo mesmo ou quando a compreensão de segunda ordem dos conteúdos parte de uma posição exterior, seja ela como uma condição de normalidade dentro da cultura capitalista contemporânea, um senso comum, ou como uma estratégia neoliberal dentro de empresas que incentivam seus funcionários (por vezes de forma agressiva) a "trazerem ideias" para o ambiente de trabalho e tornarem-se "pró-ativos", não dependendo de ordens superiores para serem produtivos ou buscarem sucesso profissional. Daí segue-se que ocorrem diversas formas de desconexão entre conteúdos de primeira ordem e reflexibilidade de segunda ordem necessária para a obtenção de autenticidade, inúmeras vezes corrompida por uma espécie de autorreconhecimento viciada que legitima o indivíduo como parte integrante de uma força produtiva calcada em uma sociedade capitalista pós-fordista, desempenhando um papel ideológico - ainda que inconsciente - na desinstitucionalização e desregulação neoliberal.

Honneth não procura explicar os sintomas de vazio e falta de propósito que surgem de demandas institucionalizadas por autorrealização autêntica a partir de uma única causa ou como um resultado de manipulações de interesses do capital entranhadas na sociedade. O que ele argumenta é que uma teoria social pode identificar afinidades entre distintos processos de desenvolvimento, cada um possuindo sua dinâmica e método, que não obstante se aglutinam na formação social. Conforme observa Zurn, Honneth acerta em não cair em um monismo interpretativo ou em estabelecer um dualismo irreconciliável entre formas de interpretação funcionalistas ou hermenêuticas:

[...] without falling prey to the errors of explanatory monism that plague not just Marxist economism but also Hegelian idealism, and without introducing unbridgeable dualisms between functional and hermeneutic forms of explanation, social theory is used to identify in a piecemeal fashion the similar direction 
tendencies of distinct and often unrelated societal transformations.(ZURN, 2011,p. 360)

Do ponto de vista metodológico, a teoria social de Honneth identifica seis ${ }^{18}$ diferentes formas de processos de desenvolvimento que fazem emergir a paradoxos de individualismo institucionalizados, trazendo suporte para explicar os diagnósticos das patologias sociais. Em primeiro lugar, estão as alterações nas estruturas sociais através das quais os indivíduos se libertam das amarras e estilos de vida das sociedades tradicionais, experimentando um aumento no grau de liberdade para definir suas próprias vidas, conforme abordado por sociólogos como Durkheim, Simmel e Weber. Em segundo lugar, o movimento de passagem do modelo industrial fordista de organização econômica para um modelo pós-fordista, passada a Segunda Guerra Mundial, onde os empregados são incentivados a autossuficiência, criatividade e ambição de ascensão empresarial, fez com que a autorrealização passasse a ser uma força produtiva no desenvolvimento econômico. Em terceiro lugar, aparece a emergência de movimentos sociais a partir dos anos 1960 e 1970, como o movimento feminista e o movimento hippie no quesito do amor livre, calcados no ideal de individualidade como valor último de orientação. Em quarto lugar, encontra-se a mudança da comunicação para meios eletrônicos, disseminando modelos de autenticidade baseados em celebridades, insuflando determinados estilos de vida e tornando difusa as linhas entre ficção e realidade. Em quinto lugar, aparecem as propagandas como forma de difundir as necessidades de consumo dentro de uma estrutura econômica capitalista, instrumentalizando os ideais de autenticidade empacotando itens de consumo como recursos de valor estético, para que cada pessoa possa "adquirir seu próprio estilo de vida". Por último, há um intercâmbio dialético entre programas políticos neoliberais de desmantelamento do estado de bemestar social e o aumento de ideias de autorresponsabilidade, individualismo atomista, ideais que os canalizaram e realizaram através de formas pré-organizadas de autorrealizações "autênticas".

Honneth assinala que, nos últimos trinta anos, as sociedades ocidentais vêm experimentando uma alteração na forma com que a autorrealização se apresenta, agora não mais 
como apenas um objetivo de vida a ser perseguido, mas também com pesadas consequências:

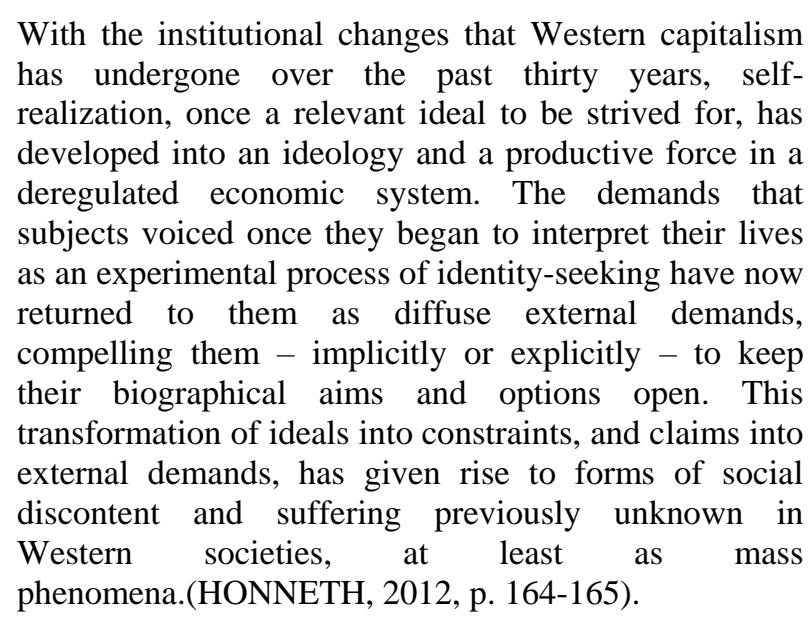

Além disso, buscando apoio teórico no sociólogo francês Alain Ehrenberg, Honneth argumenta que o uso de fármacos antidepressivos em grande escala vem crescendo com o passar dos anos, evidenciando a substituição da neurose pela depressão. Por trás disso, encontrasse a ideia de que os indivíduos estão sendo sobrecarregados psicologicamente pelas altas demandas do dia a dia, sobretudo a do que eles deveriam ser, ou seja, a busca pela constituição de uma identidade pessoal. O filósofo observa que há uma compulsão permanente de se esboçar a vida interna das pessoas com o intuito de procurar aquilo que é necessário para que as demandas de autorrealização dos sujeitos, o que acaba formando uma espécie de introspecção que em certo momento precisa encontrar uma válvula de escape. $\mathrm{O}$ momento no qual a depressão começa está atrelado ao ponto em que as experiências psicológicas do sujeito não conseguem mais indicar o caminho a ser seguido. Isso ilustra um momento histórico onde as pretensões de autorrealização deixam de ser satisfatórias e as sensações de vazio interior ganham terreno nas vidas de uma parcela crescente da população. Uma vez que são compelidas psicologicamente à busca de uma identidade autêntica, cabe aos indivíduos duas saídas: fingir autenticidade ou cair em depressão; acabam sendo forçados a escolher entre encenar publicamente uma autorrealização que não existe de fato ou se fechar para o mundo, desenvolvendo uma doença psicológica $^{19}$. 


\section{Sentimentos de injustiça e tratamentos das patologias}

De acordo com as informações até aqui expostas, os indivíduos que sofrem desrespeitos acabam por não conseguir se desenvolver de forma adequada dentro da vida em sociedade, carregando consigo as marcas psíquicas desses desrespeitos sofridos. Estes, divididos em três categorias opostas às esferas de reconhecimento, a saber: maus-tratos/violação, privação de direitos e degradação social, são considerados por Honneth como patologias sociais. Apesar de possuírem uma carga extremamente negativa, essas "doenças" são responsáveis por impulsionar as lutas por reconhecimento moralmente motivadas. Veremos a seguir de que forma essas patologias, ao provocarem sentimentos de injustiça, retiram os indivíduos da apatia e os levam a uma busca por direitos; em seguida, gostaríamos de analisar se o filósofo oferece alguma forma de tratamento para essas patologias.

\section{O sentimento de injustiça e as lutas por reconhecimento}

Conforme vimos na primeira parte deste artigo, Axel Honneth fundamenta a Teoria do Reconhecimento sobre o tripé hegeliano amor, direito e solidariedade e assinala como as experiências de desrespeito afetam os indivíduos, impedindo com que alcancem uma autorrealização plena. Contudo, o desrespeito sofrido pelos sujeitos possui um papel especial dentro das lutas por reconhecimento, pois aqueles que padecem da denegação do reconhecimento intersubjetivo esperado acabam experimentando um sentimento de injustiça. $\mathrm{O}$ filósofo argumenta que este afeto por si só não é capaz de expor o cerne normativo dessas lutas por reconhecimento, servindo antes como um diagnóstico de um problema ainda sem solução. Para que tal sentimento de injustiça possa, portanto, receber uma conotação política relevante, é necessário que se estabeleça um movimento popular que se engaje no embate por mudanças do quadro negativo. Contudo, uma luta que ambicione ser considerada social necessita, segundo Honneth, partir de um desrespeito universalizável, ou seja, uma "fratura" que atinja a vários indivíduos, fazendo com que os objetivos das pessoas 
transcendam seus objetivos particulares em favor de melhorias coletivas.

Tendo essa argumentação do filósofo em mente, podemos dizer que, segundo a sua posição, os maus-tratos e as violações são menos universalizáveis do que as privações de direitos ou a degradação social, pois o número de indivíduos atingidos é menor no primeiro caso do que no segundo. Naturalmente, Honneth não menospreza a gravidade de tamanho ato de violência, colocando-o em uma escala valorativa inferior às demais, visto que as consequências psicológicas que as vítimas sofrem perduram por muito tempo; ele apenas observa que esta espécie de barbárie se liga diretamente a experiências contra o sujeito e não contra um grupo inteiro deles, dificultando uma mobilização que dará origem a uma luta social por não ser compartilhada por toda uma coletividade. Assim, fica evidente que as lutas por reconhecimento devem possuir grande expressividade e abrangência para abarcar as reivindicações de mudanças sociais aplicadas à determinada comunidade, fazendo com que se abra um horizonte de motivações que propiciará o esclarecimento entre os sentimentos de injustiça e as lutas coletivas por reconhecimento.

Honneth encontra no sentimento de injustiça um motor moral que impulsionará os indivíduos a uma busca pela ampliação dos seus direitos e a conquista do devido reconhecimento intersubjetivo, jurídico e social. Seguindo de perto os estudos de E.P. Thompson e Barrington Moore Jr., o filósofo sustenta que inseridos nos acontecimentos históricos há uma evolução moral que se torna visível a partir da lógica da ampliação das relações intersubjetivas de reconhecimento. Dessa forma, as lutas por reconhecimento estabelecem um modelo para interpretarmos o surgimento das lutas sociais e do desdobrar-se de uma evolução moral. Podemos citar, por exemplo, a conquista de direitos igualitários entre brancos e negros (conforme idealizado por Martin Luther King) ou a abertura para o voto feminino. Portanto, fica claro que o modelo de luta por reconhecimento proposta por Axel Honneth oferece uma gramática moral onde os sentimentos de injustiça dialogam entre si e estabelecem um novo caminho que visa a ampliação das formas de reconhecimento. 


\section{Como tratar as patologias sociais?}

Conforme acompanhamos, as patologias sociais são um ponto em comum nos sistemas dos filósofos da Teoria Crítica, apontando as consequências negativas que os indivíduos podem sofrer na vida em sociedade contemporânea, variando de uma geração à outra o enfoque das suas origens. Contudo, ainda que Honneth as investigue e delimite as suas causas, não estabelece um sistema específico quanto a elas, deixando a forma com que lida com esses problemas contemporâneos de forma fragmentada. Christopher Zurn, um dos seus interlocutores mais relevantes nos últimos anos, ressalta que, ainda que o filósofo tenha se dedicado na última década a "reanimar uma tradição antiga da filosofia social" 20 , ainda falta um estudo etiológico mais coeso. Em resposta a esta crítica, diz Honneth: "Zurn is right in observing that I have not yet arrived at such a unified etiology of social pathologies. Although I have made several attempts to take steps toward explaining the social causes for second-order disorders, no consistent pattern has emerged" (HONNETH, 2011).

Apesar de não haver um sistema fechado das patologias, onde aparecem não somente as causas mas também soluções para elas, na forma como tratamos um corpo enfermo, Honneth argumenta que os indivíduos que padecem desses problemas devem buscar, como saída para a dificuldade, romper com as rotinas comportamentais do dia a dia, incluindo dentro de uma corrente causal as ocorrências daquilo que é compreensível, interpretável e alterável por parte destes indivíduos que sofrem com essas patologias. Diz o filósofo:

As long as we rely on an approach that assumes a systematic and anonymous transformation as the cause of pathologies, we will find ourselves outside of all lifeworld experience and therefore be incapable of proposing initiatives for practical change. We can only overcome this break with everyday practices if we include among these causational developments occurrences that are comprehensible, interpretable and changeable from the perspective of those affected. (HONNETH, 2011, p. 419). 


\section{Considerações finais}

Conforme acompanhamos no decorrer do presente artigo, a categoria representada pelas patologias sociais recebe um caráter importante para os estudos realizados pela Teoria Crítica, ainda que sob abordagens diferenciadas dadas pelos seus integrantes desde a sua gênese. $\mathrm{O}$ estudo do tema tendia a ser uma análise dos diagnósticos de enfermidades - geralmente psíquicas - causadas pela vida dentro das sociedades capitalistas no Ocidente, sendo estas sociedades e as implicações do capitalismo o objeto de estudo da Escola de Frankfurt. Contudo, a análise desse problema comumente fica no campo descritivo e, com Honneth, não é diferente.

Ainda que essa categoria já seja abordada no seu livro capital Luta pelo reconhecimento, publicado na Alemanha em 1992, ela não é vista pelo filósofo como um ponto fulcral do seu trabalho. Mesmo que as patologias sociais se configurem a partir dos desrespeitos sofridos pelos indivíduos, levando a enfermidades psíquicas, elas desempenham nessa obra apenas um papel secundário para os conflitos sociais.

Contudo, nos últimos dez anos, Axel Honneth vem se dedicando à análise da extensa categoria conceitual das patologias sociais, publicando seus resultados em papers e livros. Mesmo com os seus esforços, o autor não consegue estabelecer um denominador comum ou uma sistematização etiológica efetiva para elas nem oferece uma saída prescritiva para tais enfermidades. O que o filósofo ressalta é que uma análise externa ao problema, que considera apenas causas anônimas e meras transformações sistêmicas, não ajuda na compreensão e solução do mesmo. Apenas uma posição que permite a inclusão de um desencadeamento causal claro o suficiente para que os envolvidos consigam vislumbrar o princípio das patologias de forma "compreensível, interpretável e variável", a partir dos seus pontos de vista, ou seja, internamente, logrará êxito.

Agindo dessa forma, Honneth não oferece uma "solução" para as patologias sociais, mas nos dá uma pista de um possível caminho a ser seguido para o "tratamento" dessas enfermidades. Agora, como o filósofo prosseguirá com o estudo desse problema e como conduzirá sua investigação, somente o futuro irá nos responder. O que podemos afirmar é que se trata de um 
assunto muito instigante e complexo, sendo impossível de ser esgotado em um único paper.

\section{Referências}

DERANTY, Jean-Philippe. Beyond communication: a critical study of Axel Honneth's social philosophy. Social and Critical Theory, Vol. 7, Leiden: Brill, 2009, 500 p.

HONNETH, Axel. Integrity and disrespect: principles of a conception of morality based on the Theory of Recognition. In: Political Theory, Maio de 1992, pp. 187-201.

- Luta por reconhecimento: a gramática moral dos conflitos sociais. São Paulo: Ed. 34, 2003, 291 p. 2005, pp. 89-135.

Reification. In: Tanner lectures on human values,

. Sofrimento de indeterminação: uma reatualização da filosofia do direito de Hegel. São Paulo: Esfera Pública, 2007, $188 \mathrm{p}$.

Pathologies of reason: on the legacy of Critical Theory. New York: Columbia University Press, 2009, 222 p.

- Disrespect: the normative foundations of critical theory. Malden: Polity Press, 2008, 296 p.

. Rejoinder. In: PETHERBRIDGE, Danielle (ed.). Axel Honneth: critical essays. Social and Critical Theory, Vol. 12, Leiden: Brill, 2011, 440 p.

. The I in We: studies in Theory of Recognition.

Malden: Polity Press, 2012, 240 p.

MATTOS, Patrícia. Axel Honneth: formas de desrespeito social. In :Revista Mente, Cérebro e Filosofia, n.8, 2008, p. 58-67.

PETHERBRIDGE, Danielle. Axel Honneth's Project of Critical Theory. In: PETHERBRIDGE, Danielle (ed.). Axel Honneth: critical essays. Social and Critical Theory, Vol. 12, Leiden: Brill, 2011, 440 p.

SAAVEDRA, Giovani Agostini. A teoria crítica de Axel Honneth. In: SOUZA, Jessé (org); MATTOS, Patrícia (org). Teoria crítica no século XXI. São Paulo: Annablume, 2007, 324 $\mathrm{p}$.

ZURN, Christopher. Social pathologies as second-order disorders. In: PETHERBRIDGE, Danielle (ed.). Axel Honneth: 
critical essays. Social and Critical Theory, Vol. 12, Leiden: Brill, 2011,

$440 \mathrm{p}$.

${ }^{1}$ Diz Honneth: "Se a experiência de desrespeito sinaliza a denegação ou a privação de reconhecimento, então, no domínio dos fenômenos negativos, devem poder ser reencontradas as mesmas distinções que já foram descobertas no domínio dos fenômenos positivos". HONNETH, 2003. p. 214.

${ }^{2}$ Cf. HONNETH, 1992, p. 191.

${ }^{3}$ Cf. HONNETH, 2003, pp. 217-218.

${ }^{4}$ SAAVEDRA, 2007, p.109.

${ }^{5}$ Cf. ZURN, 2011, p. 347.

${ }^{6}$ Idem.

${ }^{7}$ Ibidem, p. 349.

${ }^{8}$ Cf. ibidem, p. 354.

${ }^{9}$ Cf. PETHERBRIDGE, 2011, p. 28.

${ }^{10} \mathrm{Cf}$. ZURN, 2005, pp. 355.

${ }^{11}$ Cf. HONNETH, 2005, pp. 130-1.

${ }^{12}$ Idem.

${ }^{13}$ ZURN, 2011, p. 356.

${ }^{14}$ Ibidem, p. 357.

${ }^{15}$ Idem.

${ }^{16}$ Cf. HONNETH, 2012, pp. 153-168.

${ }^{17}$ Cf. ZURN, 2011, p. 359

18 Seguimos aqui o modelo de exposição cronológico empregado por Christopher Zurn no artigo Social Pathologies as Second-Order Disorders, de 2011.

${ }^{19}$ Cf. HONNETH, 2012, pp. 165-6.

${ }^{20}$ ZURN, 2011, p. 345. 